\title{
Efecto del ácido acetil salicílico sobre el comportamiento agronómico de la papa (Solanum tuberosum L.)
}

\author{
S.E. Contreras-Liza ${ }^{1 / *}$, D. Huamán-Tasa ${ }^{1}$, H.W. Noriega-Cordova ${ }^{1}$ \\ Recibido: 08/03/2016
}

Aceptado: $24 / 11 / 2017$

Acceso en línea: Diciembre 2017

\section{Resumen}

El ácido salicílico participa en la regulación de la respuesta de la planta a una serie de estreses ambientales como temperaturas extremas, salinidad y condición oxidativa de la producción de papa. El objetivo de la investigación fue evaluar el efecto de dosis de ácido acetil-salicílico sobre el comportamiento agronómico de dos cultivares de papa en el Valle de Cañete (Perú). Se utilizó un DBCA con 3 repeticiones bajo arreglo de parcelas divididas en el que cinco dosis de ácido acetil-salicílico $(0.0,0.2,0.4,0.6$ y $0.8 \mathrm{mM})$ más un control (Biol, bioestimulante) se asignaron a subparcelas y dos cultivares de papa (Perricholi y Única), a parcelas. La temperatura media fue de 15 a $21^{\circ} \mathrm{C}$ y la humedad relativa ambiental entre 61 y $73 \%$; el suelo fue de clase textural franco y libre de sales. Se hallaron diferencias significativas $(\mathrm{p}<0.05)$ entre genotipos de papa para la mayoría los caracteres como emergencia a los 15 días, número de tallos por planta, altura de planta, porcentaje de floración, incidencia de virosis, peso de follaje, peso de tubérculos, número de tubérculos y porcentaje de sobrevivencia a la cosecha. Las dosis de ácido acetil-salicílico exhibieron diferencias estadísticas para emergencia, vigor vegetativo y porcentaje de floración; asimismo interacciones significativas $(\mathrm{p}<0.05)$ entre cultivares de papa y dosis de ácido acetil-salicílico para número de tallos por planta y porcentaje de floración. Ninguna dosis del producto afectó significativamente el rendimiento de papa en ambos cultivares; sin embargo, el efecto de la dosificación de ácido acetil-salicílico mejoró el desempeño del cultivo en cuanto a emergencia en campo, vigor vegetativo, número de tallos por planta, así como estimulación de la floración, respecto al control.

Palabras clave adicionales: papa, inmunidad vegetal, inductores químicos, Cañete, comportamiento agronómico.

\section{Agronomic performance of potato (Solanum tuberosum L.) by effect of acetylsalicylic acid}

\section{Summary}

Salicylic acid participates in the regulation of plant responses to a variety of abiotic stresses such as low and high temperature, salts and oxidative condition in potato production. The objective of the research was to evaluate the effect of increasing doses of acetylsalicylic acid on the agronomic performance of two potato cultivars in Cañete (Peru). It was used a RCBD with 3 replications under split plot arrangement in which 5 doses of acetylsalicylic acid (0.0, $0.2,0.4,0.6,0.8 \mathrm{mM}$ ) and a control with Biol (organic biostimulant) were assigned to

\footnotetext{
*Autor para correspondencia: scontreras@unjfsc.edu.pe

${ }^{1}$ Universidad Nacional José Faustino Sánchez Carrión, Huacho-Perú.
} 
subplots; two potato cultivars (Perricholi and Unica) were assigned to plots. Average temperatures ranged between 15 and $21^{\circ} \mathrm{C}$, air relative humidity between 61 and $73 \%$; soil textural class was frank and free of salts. Significant differences $(p<0.05)$ between potato genotypes were found for most characters such as emergence at 15 days, number of stems per plant, height of plant, percentage of flowering, incidence of viruses, weight of foliage, weight of tubers, number of tubers and percentage of survival at harvest. Doses of acetylsalicylic acid showed statistical differences for emergence, vegetative vigor and flowering percentage; also significant interactions $(\mathrm{p}<0.05)$ between potato cultivars and acetylsalicylic acid dose for number of stems per plant and percentage of flowering. No dosage of acetylsalicylic acid significantly affected potato yield in both cultivars, however the effect of acetylsalicylic acid improved crop performance in terms of increased sprouting under field conditions, vegetative vigor and number of stems per plant as well as the increase in flowering, with respect to control.

Additional keywords: potato, chemical elicitors, acetylsalicylic acid, Cañete, agronomic performance.

\section{Introducción}

En la región Lima, Perú, se cultivaron alrededor de 6,266 has de papa durante la campaña agrícola 2013-2014 con un rendimiento medio de $23.7 \mathrm{t} \mathrm{ha}^{-1}$, según datos de la Oficina de Estudios Económicos y Estadísticos del Ministerio de Agricultura y Riego (MINAGRI 2014). Perú es centro de origen de la papa y sus parientes silvestres, por lo que es conveniente desarrollar nuevas tecnologías de manejo agronómico con menor impacto sobre el ecosistema ya que el uso de plaguicidas químicos en la papa está aumentando en los países en desarrollo, conforme los agricultores intensifican la producción (FAO 2008a); asimismo, las virtudes de la papa, en particular su valor nutritivo y su capacidad de incrementar los ingresos del agricultor, no han sido objeto de la atención que merecen de los gobiernos, por ello es necesario invertir en nuevas tecnologías con potencial para reducir los riesgos del cultivo (FAO 2008b).

Algunas señales de compuestos de bajo peso molecular, incluyendo al ácido jasmónico, etileno y ácido salicílico, regulan la expresión de los genes relacionados con la defensa contra patógenos de las plantas (Vallad \&
Goodman 2004). Con el uso de estos reguladores, la planta afina su expresión de genes de defensa contra los agresores que, en algunos casos, pueden ser capaces de alterar o ampliar las vías de señales de defensa (Reymond \& Farmer 1998). El ácido salicílico (SA) es una molécula relacionada con la respuesta al estrés en las plantas (Hayat y Ahmad 2007) y, por lo tanto, considerada como candidata para aplicaciones exógenas como activador de resistencia sistémica inducida; en particular, el ácido acetil salicílico (ingrediente activo de la aspirina) es un compuesto fenólico análogo del SA, que ha sido identificado como un producto de bajo costo y no fitotóxico (Raskin 1992). Provocada normalmente por una infección local, las plantas responden con una cascada de señalizaciones dependientes del SA que conducen a la expresión sistémica de resistencia de amplio espectro y a una resistencia duradera que es eficaz contra hongos, bacterias e infecciones virales.

La resistencia inducida tiene potencial de revolucionar el control de enfermedades en los cultivos, pero sigue siendo un tipo de protección de cultivos no convencional (Walters et al. 2013). Los resultados de numerosas investigaciones realizadas durante las dos últimas décadas han demostrado que el SA juega un papel importante en varios aspectos de las 
respuestas de defensa posteriores al ataque de un patógeno (Vlot et al. 2009). Estas incluyen la activación de la muerte celular, la expresión de proteínas PR, así como la inducción de la resistencia local y sistémica a enfermedades (Hayat y Ahmad 2007), entre otras. Resulta interesante, por lo tanto, seguir explorando las vías de señalización de esta molécula en el contexto de la resistencia a enfermedades en los cultivos (Delaney et al. 2007). Asimismo, es necesario evaluar el efecto de dosis del SA, ya que como toda fitohormona, requiere una especificidad para su acción en la inducción de defensas en las plantas (Van Loon 2007). La debilidad del SA es que su vida dentro de la planta es muy corta siendo inmovilizada en las paredes celulares, por lo cual, para poder mantener altos niveles de resistencia, se vuelve necesaria la aplicación rutinaria durante toda la vida del cultivo (USAID 2006).

La eficiencia en la obtención de plántulas de papa sin infección de virus por termoterapia aumentó de $30.6 \%$ al $72.2 \%$ en plántulas tratadas con SA (GonzalesPasayo y Huarte 2011). La importancia del ácido salicílico en la multiplicación viral del PVY y en los síntomas fue confirmada por Baebler et al. (2011). con el desarrollo de síntomas pronunciados en la variedad de papa transgénica NahG-Desiree desprovista de SA y la reversión del efecto después de la pulverización con el ácido 2,6-dicloroisonicotínico, un compuesto análogo al SA. Halim et al. (2007) determinaron en plantas de papa $\mathrm{NahG}$ transgénicas incapaces de acumular SA, un incremento del crecimiento de patógenos y de la susceptibilidad de las plantas transformadas. Estas mismas plantas previamente tratadas con el análogo 2,6 ácido dicloro-isonicotínico del SA permitieron el crecimiento de patógenos a un nivel similar al de las plantas no transgénicas, lo que indica que es un compuesto importante que se requiere para la defensa basal de la papa contra $P$. infestans. Sin embargo, tal como lo consideran Vallad y Goodman (2004), existen limitaciones que pueden obstaculizar el uso práctico de los inductores químicos y biológicos, ya que las plantas requieren un ajuste energético al desplegar estas defensas en términos de crecimiento vegetativo y reproductivo.

A pesar de los altos niveles basales de SA que tiene naturalmente la papa, responde a la aplicación exógena de SA en una concentración baja de $250 \mathrm{uM}$, cuando se pulveriza sobre las plantas. Sin embargo, las plantas cultivadas en condiciones de campo parecen menos sensibles en determinados momentos. Algunas variedades de papa son capaces de mantener niveles de SA tan bajos como 0,5\% del total (Navarroa y Mayoa 2004).

Los tratamientos con SA estimularon significativamente la producción de etileno en rodajas de papa durante 24 horas de envejecimiento. Con $90 \mathrm{uM}$ de SA, la estimulación se correlacionó positivamente con las concentraciones aplicadas. El SA mostró un máximo efecto de estimulación sobre la producción de etileno a $\mathrm{pH}$ 6.4. Estos resultados muestran que el SA aumenta la formación de etileno endógeno en rebanadas de tubérculos de papa. Este efecto de la estimulación del SA es diferente de la concepción general de que en última instancia el SA inhibe la biosíntesis de etileno en las plantas (Liang et al. 1997). Zhang et al. (2013) consideran que la enzima ácido salicílico 3-hidroxilasa regula la longevidad de la hoja en Arabidopsis por medio del catabolismo del SA.

De acuerdo con González-Gallegos (2015), la producción de SA en plantas de papa se manifestó mediante la inoculación con Bacillus spp. y Pseudomonas fluorescens, lo cual condujo a un aumento de la resistencia a enfermedades de las plantas. 
El objetivo de la investigación fue determinar el efecto que tiene el ácido acetil salicílico -un compuesto farmacológico derivado del ácido salicílico- sobre el comportamiento agronómico de dos cultivares comerciales de papa bajo condiciones de cultivo de la Costa Central del Perú, específicamente en el Valle de Cañete.

\section{Materiales y métodos}

\section{Características del Lugar Experimental:}

El experimento se llevó a cabo en condiciones de campo durante la época de invierno en la localidad de San Isidro, distrito de Imperial, provincia de Cañete (Perú). Las temperaturas medias estuvieron en el rango de 15 a $21^{\circ} \mathrm{C}$, la humedad relativa ambiental entre 61 y $73 \%$, con un promedio de 2 horas diarias de sol y $3 \mathrm{~mm}$ diarios de evaporación. El suelo fue de clase textural franco, $\mathrm{pH} 7.5$, con $0.7 \%$ de materia orgánica, 44 ppm de fósforo y 169 ppm de potasio. Se aplicó la dosis de fertilización 100-80-60 y una tonelada de estiércol cernido por hectárea, según el análisis de suelos realizado.
Materiales: Se utilizó como material vegetal a dos cultivares de papa, Única (CIP 392797.22 y Perricholi (CIP 374080.5) proporcionados por el Centro Internacional de la Papa (Lima), que son variedades comerciales para consumo directo en Perú. Los tubérculos semilla con un peso promedio de $100 \mathrm{~g}$. para el cv. Unica y 150 g. para Perricholi, se desinfectaron con Benlate (Benomyl®) y cuando estuvieron debidamente brotados, se sembraron. Por otro lado, se formularon las dosis de SA utilizando el producto farmacológico comercial aspirina ${ }^{\circledR}$ diluyéndolo a las concentraciones de 0.2 , 0.4, 0.6 y $0.8 \mathrm{mM}$ en agua destilada (tabla 1). Se incluyó un tratamiento orgánico con Biol (producto comercial líquido) a una concentración de $1 \%$, además de un control absoluto sin SA. Asimismo se utilizó pesticidas de uso agrícola para el control de mosca minadora (Lyriomiza spp.), ácaro hialino y Alternaria spp., como parte del control de plagas; no se aplicaron fungicidas durante la campaña del cultivo.

Tabla 1. Tratamientos utilizados en el experimento.

\begin{tabular}{cll}
\hline Código & Tratamiento & Concentración $^{1}$ \\
\hline $\mathbf{0}$ & Control $^{2}$ & Sin aplicación \\
$\mathbf{1}$ & Biol $^{2}$ & $1 \%$ \\
$\mathbf{2}$ & Ácido acetil salicílico $^{\text {Ácido acetil salicílico }}$ & $0.2 \mathrm{mM}$ \\
$\mathbf{3}$ & Ácido acetil salicílico $^{2}$ & $0.4 \mathrm{mM}$ \\
$\mathbf{4}$ & Ácido $^{\mathrm{mM}}$ \\
$\mathbf{5}$ & Ácido acetil salicílico & $0.8 \mathrm{mM}$
\end{tabular}

${ }^{1}$ Tomando en cuenta la formulación comercial del producto y el peso molecular del ácido acetil salicílico.

${ }^{2}$ Se usó una dosis comercial del producto comercial Biol al $1 \%$.

durante el ciclo biológico del cultivo (105 días). La primera aplicación fue en inmersión de tubérculos-semilla; las siguientes aplicaciones fueron asperjadas al follaje, con una frecuencia quincenal a partir de la emergencia en campo. El volumen de agua aplicado dependió del tamaño del follaje de las plantas, manteniendo la concentración de los tratamientos. Las plantas de las parcelas con el tratamiento control se asperjaron con agua corriente.

Características evaluadas: Se evaluaron las siguientes características agronómicas: densidad de tallos por unidad experimental a los 15 días de la siembra, número de brotes por planta a los 30 días, vigor vegetativo (escala fenotípica, 1: muy deficiente vigor - 9: excelente vigor), altura de planta, porcentaje de floración, porcentaje de plantas con virus (los datos fueron trasformados a raíz cuadrada más 1), porcentaje de sobrevivencia a la cosecha, peso fresco de follaje por planta, número de tubérculos por planta, peso de tubérculos/planta y peso fresco de la biomasa por hectárea $\left(\mathrm{kg} \mathrm{ha}^{-1}\right)$. 
Diseño Experimental y Análisis Estadístico: Se utilizó el Diseño de Bloques Completos al Azar con tres repeticiones, bajo un esquema de parcelas subdivididas en el que los tratamientos inductores con ácido acetil salicílico y el control se asignaron a sub-parcelas (6) y los cultivares (2) a parcelas. El tamaño de la unidad experimental básica (subparcela) fue de 60 plantas por tratamiento $\left(18.5 \mathrm{~m}^{2}\right)$ y el área experimental total fue de $640 \mathrm{~m}^{2}$. Los datos se analizaron estadísticamente a un nivel de confianza del $95 \%$, mediante el análisis de la variancia. Los promedios de los tratamientos se compararon usando la prueba de Tukey (Steel et al. 1997) a un nivel de significación 0.05 y los datos se procesaron mediante el programa Infostat (Balzarini et al. 2015).

\section{Resultados y discusión}

En la Tabla 2, se observa que los tratamientos aplicados con SA y Biol, afectaron la variabilidad de caracteres agronómicos como densidad de tallos por unidad experimental, vigor vegetativo y el porcentaje de floración y se presentaron algunas interacciones significativas entre las variedades de papa y los tratamientos aplicados con ácido acetil salicílico para densidad de tallos, número de tallos por planta y floración.

Tabla 2. Análisis de variación para caracteres agronómicos en 2 cultivares de papa bajo efecto de ácido acetil salicílico.

\begin{tabular}{|c|c|c|c|c|c|c|c|c|c|c|c|c|}
\hline \multirow{2}{*}{$\begin{array}{c}\text { Fuentes de } \\
\text { Variación }\end{array}$} & \multirow{2}{*}{$\begin{array}{c}\text { Grados de } \\
\text { Libertad }\end{array}$} & \multicolumn{11}{|c|}{ Cuadrados Medios } \\
\hline & & DTallos 15d & NTallos.pl & Vigor & APlant & $\%$ Virus $^{1}$ & $\%$ Floracion & PFollaje.pl & NTuberc.pl & PTuberc.pl & $\%$ Sobreviv. & Biomasa ha \\
\hline Repeticiones & 2 & 937.8 & 0.06 & 1.37 & 54341 & 0.009 & 4.6 & 0.020 & 12.3 & 0.04 & 1.41 & 156278 \\
\hline Cultivares & 1 & $1653.8^{*}$ & $1.09 *$ & 0.06 & $33180 *$ & 34. 03* & $16691.4^{*}$ & $0.041 *$ & $11.6^{*}$ & $0.14 *$ & $918.0^{*}$ & $275151 *$ \\
\hline Dosis & 5 & 925.9* & 0.32 & $0.35^{*}$ & 45,00 & 0.16 & $43.5^{*}$ & 0.009 & 0.8 & 0.01 & 80.0 & 48263 \\
\hline Error a & 10 & 564.5 & 0.20 & 0.09 & 17,00 & 0.08 & 14.2 & 0.003 & 1.43 & 0.01 & 143.0 & 22198 \\
\hline Cultivares. Dosis & 5 & $1099.1^{*}$ & $0.49 *$ & 0.11 & 18,00 & 0.71 & $43.5^{*}$ & 0.007 & 2.07 & 0.008 & 10.5 & 30039 \\
\hline Error b & 12 & 250.9 & 0.12 & 0.08 & 23,00 & 0.44 & 12.6 & 0.005 & 2.2 & 0.01 & 13.7 & 30019 \\
\hline Total & 35 & & & & & & & & & & & \\
\hline Promedio & & 87.90 & 2.63 & 7.06 & 47.42 & 2.24 & 19.04 & 0.31 & 5.4 & 0.48 & 93.17 & 29601 \\
\hline $\mathrm{R}^{2}$ & & 0.87 & 0.83 & 0.86 & 0.93 & 0.88 & 0.99 & 0.78 & 0.71 & 0.77 & 0.87 & 0.77 \\
\hline $\mathrm{CV}, \%$ & & 17.13 & 13.05 & 4.02 & 9.65 & 29.7 & 16.48 & 20.74 & 26.23 & 19.97 & 3.92 & 17.68 \\
\hline Unidades & & $\mathrm{n}$ & $\mathrm{n}$ & Escala 1-9 & $\mathrm{cm}$. & $\sqrt[1]{ }(\%+1)$ & $\%$ & $\mathrm{~kg}$ & $\mathrm{n}$ & $\mathrm{kg}$ & $\%$ & $\mathrm{~kg}$ \\
\hline
\end{tabular}

*Valores de los cuadrados medios en negrita* fueron estadísticamente significativos $(P<0.05)$, DTallos $15 \mathrm{~d}=$ densidad de tallos por unidad experimental a los 15 días, NTallos•pl = número de tallos por planta a los 30 días Vigor $=$ vigor vegetativo $($ escala fenotípica 1-9), APlant $=$ altura de planta en $\mathrm{cm}, \%$ Floración $=$ porcentaje de floración, $\%$ Virus $^{1}=$ porcentaje de plantas con virus (datos trasformados a raíz cuadrada más 1 ), \% Sobreviv. = porcentaje de plantas sobrevivientes a la cosecha, PFollaje $\cdot$ pl. = peso fresco de follaje por planta, NTuber $\cdot$ pl. $=$ número de tubérculos por planta, PTuberc $\cdot \mathrm{pl} .=$ peso fresco de tubérculos, $\mathrm{kg} \cdot \mathrm{planta}^{-1}$, Biomasa $\cdot$ ha $=$ peso total de la biomasa $\left(\mathrm{kg} \cdot \mathrm{ha}^{-1}\right)$.

Existieron diferencias estadísticas para los genotipos de papa en los caracteres estudiados como emergencia a los 15 días de la siembra, número de tallos por planta, altura de planta, porcentaje de floración, incidencia de virosis, peso de follaje, peso de tubérculos, número de tubérculos y porcentaje de sobrevivencia a la cosecha.

El vigor vegetativo mostró un efecto de interacción entre cultivares de papa $\mathrm{y}$ dosificación (Tabla 3); a las dosis de 0.2 a $0.4 \mathrm{mM}$ se obtuvo un mayor efecto en el vigor del cv. Perricholi que en el cv. 
Unica, en relación al control. Este resultado podría compararse al obtenido por Mora y López (2004) quienes aplicaron un tratamiento con SA $0.1 \mathrm{mM}$ incrementando la supervivencia de microplantas de papa en los cv. Alpha y Atlantic en relación con los testigos, atribuyéndose ello a una menor actividad de la enzima catalasa.

Tabla 2. Análisis de variación para caracteres agronómicos en 2 cultivares de papa bajo efecto de ácido acetil salicílico.

\begin{tabular}{|c|c|c|c|c|c|c|c|c|c|c|c|c|}
\hline \multirow{2}{*}{$\begin{array}{l}\text { Fuentes de } \\
\text { Variación }\end{array}$} & \multirow{2}{*}{$\begin{array}{c}\text { Grados de } \\
\text { Libertad }\end{array}$} & \multicolumn{11}{|c|}{ Cuadrados Medios } \\
\hline & & DTallos $15 \mathrm{~d}$ & NTallos.pl & Vigor & APlant & $\%$ Virus $^{1}$ & \%Floracion & PFollajepl & NTuberc $\cdot \mathrm{pl}$ & PTuberc $\cdot \mathrm{pl}$ & \%Sobreviv. & Biomasa ha \\
\hline Repeticiones & 2 & 937.8 & 0.06 & 1.37 & 54341 & 0.009 & 4.6 & 0.020 & 12.3 & 0.04 & 1.41 & 156278 \\
\hline Cultivares & 1 & $1653.8^{*}$ & $1.09^{*}$ & 0.06 & $33180^{*}$ & $34.03 *$ & $16691.4^{*}$ & $0.041^{*}$ & $11.6^{*}$ & $0.14 *$ & $918.0 *$ & $275151 *$ \\
\hline Dosis & 5 & $925.9^{*}$ & 0.32 & $0.35^{*}$ & 45,00 & 0.16 & $43.5^{*}$ & 0.009 & 0.8 & 0.01 & 80.0 & 48263 \\
\hline Error a & 10 & 564.5 & 0.20 & 0.09 & 17,00 & 0.08 & 14.2 & 0.003 & 1.43 & 0.01 & 143.0 & 22198 \\
\hline Cultivares. Dosis & 5 & $1099.1^{*}$ & $0.49^{*}$ & 0.11 & 18,00 & 0.71 & $43.5^{*}$ & 0.007 & 2.07 & 0.008 & 10.5 & 30039 \\
\hline Error b & 12 & 250.9 & 0.12 & 0.08 & 23,00 & 0.44 & 12.6 & 0.005 & 2.2 & 0.01 & 13.7 & 30019 \\
\hline Total & 35 & & & & & & & & & & & \\
\hline Promedio & & 87.90 & 2.63 & 7.06 & 47.42 & 2.24 & 19.04 & 0.31 & 5.4 & 0.48 & 93.17 & 29601 \\
\hline $\mathrm{R}^{2}$ & & 0.87 & 0.83 & 0.86 & 0.93 & 0.88 & 0.99 & 0.78 & 0.71 & 0.77 & 0.87 & 0.77 \\
\hline $\mathrm{CV}, \%$ & & 17.13 & 13.05 & 4.02 & 9.65 & 29.7 & 16.48 & 20.74 & 26.23 & 19.97 & 3.92 & 17.68 \\
\hline Unidades & & $\mathrm{n}$ & $\mathrm{n}$ & Escala 1-9 & $\mathrm{cm}$. & $\sqrt[1]{(\%+1)}$ & $\%$ & $\mathrm{~kg}$ & $\mathrm{n}$ & $\mathrm{kg}$ & $\%$ & $\mathrm{~kg}$ \\
\hline
\end{tabular}

*Valores de los cuadrados medios en negrita* fueron estadísticamente significativos $(P<0.05)$, DTallos $15 \mathrm{~d}=$ densidad de tallos por unidad experimental a los 15 días, NTallos•pl = número de tallos por planta a los 30 días Vigor = vigor vegetativo (escala fenotípica 1-9), APlant $=$ altura de planta en $\mathrm{cm}, \%$ Floración $=$ porcentaje de floración, $\%$ Virus $^{1}=$ porcentaje de plantas con virus (datos trasformados a raíz cuadrada más 1 ), \% Sobreviv. = porcentaje de plantas sobrevivientes a la cosecha, PFollaje $\cdot$ pl. = peso fresco de follaje por planta, NTuber $\cdot$ pl. = número de tubérculos por planta, PTuberc $\cdot \mathrm{pl} .=$ peso fresco de tubérculos, $\mathrm{kg} \cdot \mathrm{planta}^{-1}$, Biomasa $\cdot$ ha $=$ peso total de la biomasa $\left(\mathrm{kg} \cdot \mathrm{ha}^{-1}\right)$.

La floración fue estimulada por efecto de la aplicación del ácido acetil salicílico en el cultivar Perricholi a la dosis de $0.4 \mathrm{mM}$ (Figura 1); donde dicho tratamiento superó estadísticamente al control y a la aplicación de Biol; el cultivar Única no floreció.

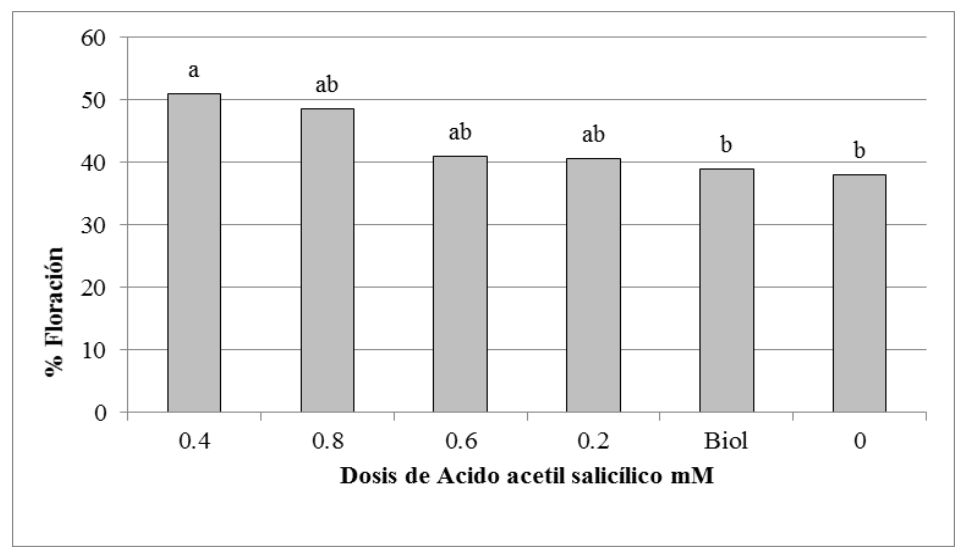

Figura 1. Efecto de ácido acetil salicílico sobre el porcentaje de floración en el cv. Perricholi en Cañete. 
Los tratamientos de ácido acetil salicílico y Biol no afectaron significativamente la biomasa por hectárea (peso fresco de tubérculos y follaje) en ambos cultivares a las dosis utilizadas (Tabla 2). Este hecho puede explicarse por efecto de la baja dosificación utilizada en el experimento; se conoce que a dosis elevadas el SA puede afectar tanto la biomasa como la producción en los cultivos por el desarrollo de las defensas en la planta, que tiene un alto costo energético (Vallad y Goodman 2004).

Para la densidad de tallos por unidad experimental, los tratamientos de Biol y ácido acetil salicílico a la dosis de $0.4 \mathrm{mM}$ incrementaron significativamente la emergencia en ambos cultivares en comparación al control, en referencia al cultivar Perricholi (Tabla 3); para el caso de número de tallos por planta a los 30 días (Figura 2) se observaron diferencias significativas entre dosis $y$ en la interacción de dosis y cultivares. Asimismo en número de tallos por planta los tratamientos con Biol o con la dosificación de ácido acetil salicílico entre 0.2 a $0.4 \mathrm{mM}$ tuvieron un efecto significativo en la variedad Perricholi para este carácter con relación al control sin aplicación, no así en el cultivar Única donde no se evidenciaron diferencias significativas para estimular el brotamiento por planta (Figura 2).

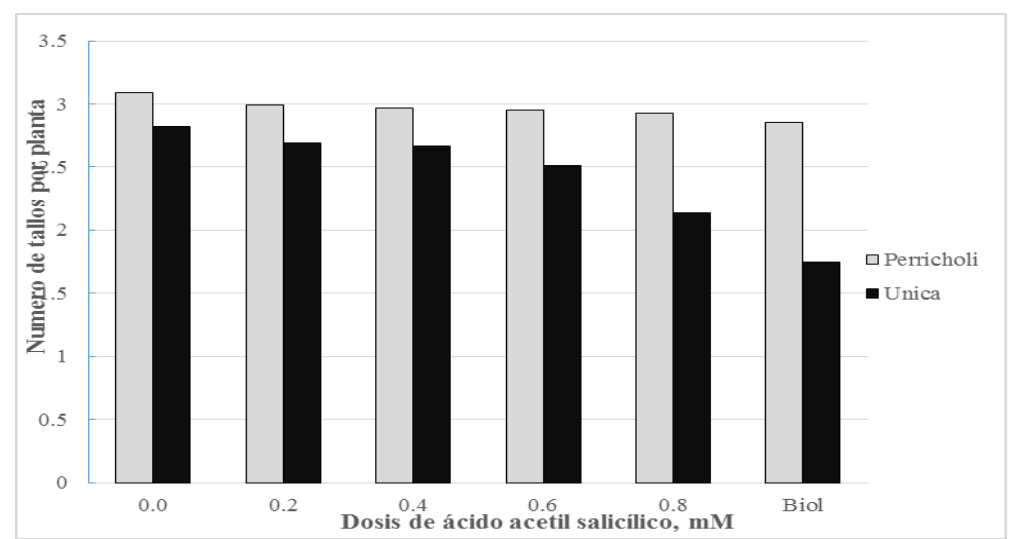

Figura 2. Efecto de ácido acetil salicílico y Biol sobre la emergencia en campo (número de tallos por planta) en dos cultivares de papa en Cañete.

Tabla 3. Efecto promedio de dosificación de ácido acetil salicílico sobre vigor y floración en dos cultivares de papa.

\begin{tabular}{lcrlrl}
\hline Cultivar & Dosis mM & Vigor & \% Floración & \\
\hline Perricholi & 0.0 & 7.67 & $\mathrm{a}$ & 50.97 & $\mathrm{ab}$ \\
Perricholi & 0.2 & $7.27 \mathrm{ab}$ & 48.64 & $\mathrm{ab}$ \\
Perricholi & 0.4 & $7.23 \mathrm{ab}$ & 41.06 & $\mathrm{ab}$ \\
Perricholi & 0.6 & $7.23 \mathrm{ab}$ & 40.65 & $\mathrm{ab}$ \\
Perricholi & 0.8 & $7.20 \mathrm{ab}$ & 38.99 & $\mathrm{~b}$ \\
Perricholi & Biol $^{1}$ & $7.20 \mathrm{ab}$ & 38.07 & $\mathrm{~b}$ \\
Unica & 0.0 & $7.17 \mathrm{ab}$ & $0.00 \mathrm{c}$ \\
Unica & 0.2 & $7.07 \mathrm{ab}$ & $0.00 \mathrm{c}$ \\
Unica & 0.4 & $7.07 \mathrm{ab}$ & $0.00 \mathrm{c}$ \\
Unica & 0.6 & $6.9 \mathrm{ab}$ & $0.00 \mathrm{c}$ \\
Unica & 0.8 & $6.87 \mathrm{ab}$ & $0.00 \mathrm{c}$ \\
Unica & $\mathrm{Biol}^{1}$ & $6.57 \mathrm{~b}$ & $0.00 \mathrm{c}$ \\
Error estándar & & 0.17 & 2.05 & \\
\hline
\end{tabular}

Medias con la misma letra en columnas no difieren significativamente $(P>0.05),{ }^{1}$ Biol a la concentración de $1 \%$. 
Los resultados muestran que los efectos de la aplicación del ácido acetil salicílico en los cultivares de papa evaluados fueron principalmente sobre caracteres relacionados con la fisiología de la planta como emergencia y densidad de tallos (Figura 2), vigor y floración al menos en algunos cultivares de papa (Figura 1) y estos resultados pueden estar en relación con el hecho que la papa responde a la aplicación exógena de ácido salicílico a una concentración relativamente baja (Navarroa y Mayoa 2004). Las dosis usadas en las frecuencias de aplicación establecidas no afectaron significativamente los pesos de tubérculos, follaje y biomasa total, por lo que pueden considerarse seguras para la aplicación en campo; se ha considerado que la planta utiliza parte de la energía en la resistencia sistémica y que podrían existir problemas de merma de producción por una sobredosificación de ácido salicílico (Vallad y Goodman 2004); asimismo, la sobredosificación puede estresar la planta causando reducción de rendimiento en los cultivos, tal como lo considera también USAID (2006).

En cuanto a los aspectos relacionados con la producción de tubérculos y de la biomasa de papa por hectárea no se hallaron diferencias por la dosificación usada de ácido acetil salicílico en la presente investigación, aunque algunos autores afirman que la aplicación exógena de SA puede mejorar la producción de fotosintatos en la papa bajo condiciones de estrés por temperatura y proteger a las plantas de papa del daño ocasionado por fitoplasmas, mejorando así la asimilación fotosintética del tubérculo (Sanchez Rojo et al. 2011), la tolerancia al estrés osmótico in vitro (Daneshmand et al. 2009), la termo-tolerancia in vitro (López-Delgado et al. 1997), la tolerancia al calor y al PVX (López-Delgado et al. 2004) o a la pudrición originada por Erwinia spp. (Lopez-López et al. 1995)
Por otro lado, a diferencia de lo hallado por Gonzáles-Pasayo y Huarte (2011), no se mostraron diferencias significativas en cuanto a la incidencia de virus en los cultivares de papa por efecto del ácido acetil salicílico, pero ello podría deberse a diversos factores entre los que se pueden destacar los genotipos de papa utilizados con diferencias en cuanto al grado de susceptibilidad frente a la virosis, así como a la incidencia de virus en condiciones de campo.

\section{Conflictos de intereses}

Los autores del artículo presentado declaran que no existe ningún conflicto de intereses. Todos los autores han contribuido en forma proporcional en la investigación y edición del presente manuscrito y se responsabilizan de la integridad y exactitud del análisis realizado a los datos.

\section{Agradecimientos}

La investigación fue financiada con fondos del Canon Regional y del Gas de Camisea (FOCAM) promovidos por el Vicerrectorado de Investigación de la Universidad Nacional José Faustino Sánchez Carrión-Huacho, que permitió la ejecución del proyecto durante el 20142015. Agradecemos al Dr. Ernesto Ormeño-Orrillo investigador de la Universidad Nacional Agraria-La Molina, por la revisión del manuscrito. Se agradece asimismo, al siguiente personal administrativo de la Universidad: Amalia Gonzales, Yuri Gamonal, Adolfo Figueroa, Rossana Garrido y María Julia Fernández.

\section{Referencias Citadas}

Baebler, S.; Stare, K.; Kovac, M.; Blejec, A.; Prezelj, N. (2011). Dynamics of responses in compatible potato - potato virus $\mathrm{Y}$ interaction are modulated by Salicylic Acid. PLoS ONE 6(12), e29009.

Balzarini, M.G., Gonzalez, L., Tablada, M., Casanoves, F., Di Rienzo, J.A., Robledo, C.W. (2015). InfoStat. Manual 
del Usuario. Editorial Brujas, Córdoba, Argentina.

Daneshmand, F., Mohammad, J. A., \& Khosrow, M. K. (2009). Effect of acetylsalicylic acid (Aspirin) on salt and osmotic stress tolerance in Solanum bulbocastanum in vitro: enzymatic antioxidants. Am Eurasian J Agric Environ Sci, 6, 92-99

Delaney, S; Uknes, S; Vernooij, B; Friedrich, L; Weymann, K; Negrotto, D; Gaffney, T; Gutrella, M; Kessmann, H; Ward, E. (1994). A central role of salicylic acid in plant disease resistance. Science 266, 1247-1250.

FAO. (2008a). Producción de tubérculos semillas libres de enfermedades. El año internacional de la papa 2008, Secretaria del año internacional de la Papa, FAO. Roma

FAO. (2008b). Gestión de las plagas y enfermedades, Secretaria del año internacional de la Papa, FAO. Roma.

González-Gallegos, E. (2015). Changes in the Production of Salicylic and Jasmonic Acid in Potato Plants (Solanum tuberosum) as Response to Foliar Application of Biotic and Abiotic Inductors. American Journal of Plant Sciences, 6, 1785-1791.

González-Pasayo, R A; Huarte M. (2011). Efecto del ácido salicílico en la eliminación de PLRV y PVY en plantas de papa. Revista Latinoamericana de la Papa, 16 (1), 58-67.

Halim, VA; Eschen-Lippold, L; Altmann, S; Birschwilks, M; Scheel, D; Rosahl, S. (2007). Salicylic Acid Is Important for Basal Defense of Solanum tuberosum against Phytophthora infestans. MPMI 20 (11), 1346-1352.

Hayat, S \& Ahmad, A. (2007). Salicylic Acid: A Plant Hormone. En: S Hayat \& A. Ahmad (Eds.), Salicylic acid: a plant hormone (pp. 247-276). Dordrecht, The Netherlands: Springer.

Liang, W.S.; Wen, J.Q.; Liang, H.G. (1997). Growth and metabolism stimulation of ethylene production in aged potato tuber slices by salicylic acid. Phytochemistry 44 (2), 221-223

López-Delgado, H., Mora-Herrera, M. E., Zavaleta-Mancera, H. A., CadenaHinojosa, M., \& Scott, I. M. (2004). Salicylic acid enhances heat tolerance and potato virus $\mathrm{X}$ (PVX) elimination during thermotherapy of potato microplants. American Journal of Potato Research, 81(3), 171-176.

Lopez-Delgado, H., Dat, J. F., Foyer, C. H., \& Scott, I. M. (1998). Induction of thermotolerance in potato microplants by acetylsalicylic acid and $\mathrm{H} 2 \mathrm{O} 2$. Journal of Experimental Botany, 49(3), 713-720.

López-López, M. J., Liebana, E., Marcilla, P., \& Beltra, R. (1995). Resistance induced in potato tubers by treatment with acetylsalicylic acid to soft rot produced by Erwinia carotovora subsp. carotovora. Journal of Phytopathology, 143 (11-12), 719-724.

MINAGRI (2014). Dinámica Agropecuaria 2003-2012. Oficina de Estudios Económicos y Estadísticos del Ministerio de Agricultura y Riego, Lima.

Mora Herrera, M. E., \& López Delgado, H. A. (2006). Tolerancia a baja temperatura inducida por ácido salicílico y peróxido de hidrógeno en microplantas de papa. Revista Fitotecnia Mexicana, 29, 81-85.

Navarroa, D.A.; Mayoa, D. (2004). Differential characteristics of salicylic acid-mediated signaling in potato. Physiological and Molecular Plant Pathology 64(4), 179-188.

Raskin, I. (1992). Role of salicylic acid in plants. Annu. Rev. Plant Physiol. Plant Mol. Biol., 43, 439-463 
Reymond, P \& Farmer, E. (1998). Jasmonate and salicylate as global signals for defense gene expression. Current Opinion in Plant Biology, 1, 404-411.

Sánchez-Rojo, S., López-Delgado, H. A., Mora-Herrera, M. E., Almeyda-León, H. I., Zavaleta-Mancera, H. A., \& EspinosaVictoria, D. (2011). Salicylic acid protects potato plants-from phytoplasma-associated stress and improves tuber photosynthate assimilation. American journal of potato research, 88(2), 175-183.

Steel, R., J., Torrie, D. A., Dickey, A. (1997). Principles and procedures of statistics: a biometrical approach. McGraw-Hill. 666 pages

USAID. (2006). El Uso del Ácido Salicílico y Fosfonatos (Fosfitos) para Activar el Sistema de Resistencia de la Planta $(S A R)$. Boletín técnico de producción, Agosto 2006, USAID-RED, Oficina FHIA, La Lima, Cortes, Honduras.
Vallad, G.E. \& Goodman, R. (2004). Systemic acquired resistance and induced systemic resistance in conventional agriculture. Crop Sci. 44, 1920-1934

Van Loon, L.C. (2007). Plant responses to plant growth-promoting rhizobacteria. Eur J Plant Pathol 119,243-254.

Vlot, A.C.; Dempsey, D.A. \& Klessig, D.F. (2009). Salicylic Acid, a multifaceted hormone to combat disease. Annu Rev Phytopathol. 47,177-206

Walters, D; Ratsep, J \& Havis, N. (2013). Controlling crop diseases using induced resistance: challenges for the future. Journal of Experimental Botany 64 (5), 1263-1280.

Zhang, K; Halitschkec, R; Yina, C; Liub, C; Gana, S. (2013). Salicylic acid 3hydroxylase regulates Arabidopsis leaf longevity by mediating salicylic acid catabolism. PNAS 113(36), 14807-14812. 